American Journal of Applied Sciences 5 (1): 34-41, 2007

ISSN 1546-9239

(C) 2007 Science Publications

\title{
Simulation of the Pedestrians' Influence to the Capacity of Motorised Vehicles in a Roundabout
}

\author{
${ }^{1} \mathrm{~T}$. Tollazzi, ${ }^{2} \mathrm{~T}$. Lerher and ${ }^{1} \mathrm{M}$. Šraml \\ ${ }^{1}$ University of Maribor, Faculty of Civil Engineering, \\ Smetanova 17, 2000 Maribor, Slovenia \\ ${ }^{2}$ University of Maribor, Faculty of Mechanical Engineering, \\ Smetanova 17, 2000 Maribor, Slovenia
}

\begin{abstract}
A new approach is suggested for dimensioning roundabouts with mathematical modeling of traffic flows using the discreet simulation method, and considering the statistically evaluated entry data for vehicles' and pedestrians' traffic flows. The simulation results are useful when determining the capacity of the roundabouts, which will function in different circumstances. The presented model derives from the expected time void in the vehicles' traffic flow, used by the pedestrians, presuming their advantage when joining into the traffic. The simulation analysis has been verified on a real example of a montage roundabout in Maribor, where measurements of motorized vehicles' traffic flow, pedestrians' and cyclists' traffic flow had taken place.
\end{abstract}

Key Words: Roundabouts, Simulation methods, Discrete model

\section{INTRODUCTION}

With one-lane roundabouts, problems with entering and exiting the roundabout can occur due to large traffic flows of pedestrians and/or cyclists. Vehicles on entries and exits should, as a rule, give priority to pedestrians and cyclists. For this reason, disturbances occur in the main vehicle flow, considered as a priority when dimensioning a roundabout intersection and its capacity for the resulting congestions ${ }^{[1]}$. When a flow of vehicles, traversed by pedestrians and/or cyclists, is oriented towards an entry, achieving the minimum capacity of the roundabout becomes questionable. When a flow of vehicles, traversed by pedestrians and/or cyclists, is oriented towards an exit, the maximum capacity gets exceeded ${ }^{[2]}$. The possibility of a roundabout blockage can occur in more ways. In the past, many authors $[4,5]$ used different ways of calculating the capacity of roundabouts and different approaches for determining the influence of the flow of non-motorized traffic participants on the capacity of a roundabout. The common feature of all the approaches is an abundance of mathematical calculations ${ }^{[6]}$ and simplifications to make the calculation possible in the first place. This is why this kind of calculation has been used in exceptional cases only. Among the simpler methods, where only a diagram or one equation are used, are the German method for determining the influence of pedestrians ${ }^{[7]}$ and the Dutch method for determining the influence of cyclists ${ }^{[8]}$ on the capacity of a one-lane roundabout.

Lately, the significance of simulation methods is increasing, with the most credit going to increasingly capable computers and the numerous possibilities for creating complex mathematical models that enable good comparability of the results with the actual circumstances. The presented model derives from the expected time void in the pedestrians' traffic flow, used by the vehicles for entering and exiting the roundabout, assuming their right of way when joining the traffic. In the proposed model only a separate arm of the roundabout is considered, without the influence of a circular flow of motorized vehicles on the circulatory roadway. The equal velocity of the motorized vehicles, as well as for pedestrians is considered. The arrivals of the pedestrians are supposed to be separate, one by one, in single file. The simulation analysis was verified on a real example of a montage roundabout in Maribor, where all the necessary traffic-flow measurements were made. The procedure, shown in the article, along with the scientific approach to mathematical modeling, presents an instrument that is helpful when deciding how reasonable it is to implement a roundabout in the case of strong traffic flows of pedestrians and/or cyclists.

Corresponding Author: $\quad$ Matjaž Šraml, University of Maribor, Faculty of Civil Engineering, Smetanova 17, SI-2000

Maribor, Slovenia 
Am. J. Applied Sci., 5 (1): 34-41, 2007

\section{MATERIALS AND METHODS}

When defining the capacity reduction of roundabouts, two different samples can be distinguished because of large traffic flows of pedestrians and/or cyclists. In the first case, the traversed pedestrian's and/or cyclist's flow influenced the permeable capacity of the roundabout, but it still works. In second case, the influence of the pedestrian's and/or cyclist's traffic flow was of such size that bottlenecks on roundabout entry and exit are possible, which could also be extended to the adjacent roundabout arms. If the length of the vehicles in the queue is so long that it stretches back to the previous entry point, problems with occupation of the roundabout arise and a blockage of the entire roundabout can occur. The mentioned problems of entering and exiting a roundabout in real conditions usually happen simultaneously. In real circumstances it is also usual that those intensive pedestrian flows traverse only one arm of the roundabout, although in some cases the pedestrians' flow "cuts" all the arms at once. In these cases the blockage of the roundabout occurs earlier. In the following is an example of when a strong pedestrian flow traverses only one arm, because of the easier explanation. The right-of way pedestrian flow traverses the south arm of the roundabout (Figure 1).

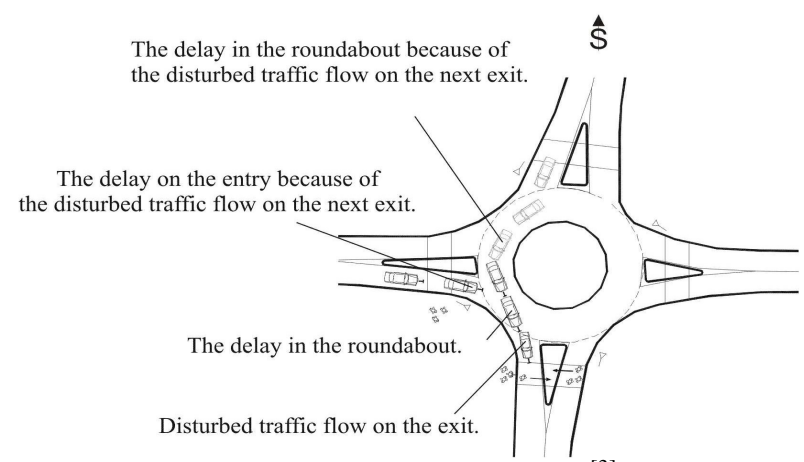

Fig. 1: Queue formation on a roundabout ${ }^{[3]}$

The time interspaces between two consecutive pedestrians are long enough; therefore, the vehicles exiting the roundabout use them and exit the roundabout undisturbed. The vehicle flow on the exit is stable in this case. With an increasing strength of pedestrian flow the time interspaces between the traffic flow units are reduced. Situations occasionally occur when the individual time interspaces between the pedestrian flow units are shorter than acceptable. In these cases the vehicle waits in the waiting place between the outside edge of the circulatory roadway and the inside edge of the pedestrian crossing. The flow is still stable, but occasionally it is disturbed.

With an additional increase in the pedestrian flow the conditions get worse and the waiting place on the exit of the roundabout becomes occupied all the time. For this reason the vehicles are congested on the circulatory roadway towards the preceding entry, thus preventing entry to the roundabout. The traffic flow between the south and the west arms is disturbed. In this case traffic flow is possible only on other parts of the circulatory roadway. In the case that one of the vehicles on the other three entries is directed towards the blocked exit, another circular segment gets filled (between the west and the north arms - Figure 1), which causes the blockage of the west arm of the roundabout. The blockage is transferred from an exit towards the preceding (opposite to the driving direction) entry to the roundabout and from here towards the preceding exit. The entire procedure can repeat itself in the direction opposite to the driving until the roundabout is completely blocked. In a one-lane roundabout with a waiting space for one vehicle in the waiting place between the pedestrian crossing and the outside edge of the circulatory roadway the following three situations can generally occur:

- time interspaces between the individual units of transverse pedestrian flow are sufficient for vehicle flow, and so there are no waiting vehicles in the waiting place;

- time interspaces between the individual units of transverse pedestrian flow are still sufficient for vehicle flow, although vehicles do wait in the waiting place;

- time interspaces between the individual units of transverse pedestrian flow are not large enough, the waiting place is occupied all the time and every next vehicle waits in the circulatory roadway. How many times these situations occur, what are the conditions for the creation of these situations, what conditions have to be fulfilled for a blockage of one arm of the roundabout and at what traffic load of pedestrians or motorized traffic flow the disturbance is transferred from one to another arm are the questions, the answers to which determine the influence of the pedestrian flow on the capacity of a one-lane roundabout. It is obvious that such complex influences and mutual actions of different variables cannot be solved without appropriate mathematical models or discreet simulations of the motorized and non-motorized traffic flows. In the following, the basic theoretical backgrounds for the mathematical analysis of a traffic flow in a given roundabout are presented. 
Am. J. Applied Sci., 5 (1): 34-41, 2007

Table 1: Geometrical and kinematics input data

\begin{abstract}
Geometrical input data
Outside diameter of the roundabout

Inside diameter of the roundabout

Width of the road

Width of the pedestrian crossing

Length of entrance road (chosen)
\end{abstract}

Length of pedestrian crossing

\section{$25 \mathrm{~m}$ \\ $17 \mathrm{~m}$ \\ $4 \mathrm{~m}$ \\ $5 \mathrm{~m}$}

Arm A - 45 m,

Arm B - $77 \mathrm{~m}$,

Arm C $-60 \mathrm{~m}$.

$12 \mathrm{~m}$

\begin{tabular}{lc}
\hline Kinematics input data & \\
\hline Acceleration $a_{M V I}$ of a motorised vehicle on the entry & $1 \mathrm{~m} / \mathrm{s}^{2}$ \\
Velocity $v_{M V I}$ of a motorised vehicle on the arm & $40 \mathrm{~km} / \mathrm{h}$ \\
Velocity $v_{M V 2}$ of a motorised vehicle near the & $20 \mathrm{~km} / \mathrm{h}$ \\
pedestrians' crossing & \\
Acceleration $a_{P K}$ of a pedestrian and a cyclist & $0,3 \mathrm{~m} / \mathrm{s}^{2}$ \\
Velocity $v_{P K}$ of a pedestrian and a cyclist & $5 \mathrm{~km} / \mathrm{h}$ \\
\hline
\end{tabular}

The analysis of traffic flows using discreet numeric simulations represents a successful way of analyzing more complex crossroads and intersections from the point of capacity determination ${ }^{[9-11]}$. Considering the complexity of the analytical model of a roundabout and the usage of a discreet simulation technique, discreet numeric simulations for the analysis of the capacity of a roundabout were used. In the proposed contribution the program code AutoMod ${ }^{[12]}$ was used for the analysis of a roundabout. AutoMod ${ }^{[12]}$ is used mostly for implementing discreet numeric simulations of internal logistic systems and all other logistic discreet systems. It offers the user a reliable tool for planning or reconstructing complex and inter-dependent systems ${ }^{[12]}$. The programming tool consists of individual programming modules that construct the programming tool AutoMod ${ }^{[12]}$ as integrity.

When modeling a general system, already built-in elements (connection transporters, automates transport vehicles, etc.) that represent certain complexes in the chosen process, can be used. In the source file characteristics, which suit to the real situation and connect them appropriately, are determined. With the help of command lines the implementation of the simulation is determined and based on the acquired results of simulations the success and the efficiency of the system is analyzed.

In the continuation steps of the simulation and the analysis of the motorized vehicles' traffic flow on a montage three-armed, one-lane roundabout with strong pedestrians' and cyclists' traffic flow on Koroska Street in Maribor are shown. The actual geometrical data are derived from Figure 2 and from a sample of pedestrians' and motorized vehicles' flows for all the arms of the roundabout and pedestrian crossings, gathered by counting traffic and statistically evaluating the acquired data.

When constructing a simulation model for a montage three-armed, one-lane roundabout the actual geometry of the roundabout (Figure 2) and the velocity characteristics of vehicles and pedestrians (Table 1) were considered. A 15-hour (6:00 to 21:00) count was performed for the requirements of the analysis, on all the intersections' arms, separately for the motorized vehicle traffic and the pedestrian and cyclist traffic (Figure 2). The results of the motorized-vehicle traffic count (Table 2) and the pedestrian/cyclist traffic count (Table 2) on the Arm A - direction "old bridge", on the Arm B - direction Koroska Street east and on the Arm C - direction Koroska Street, that are treated in this work were presented.

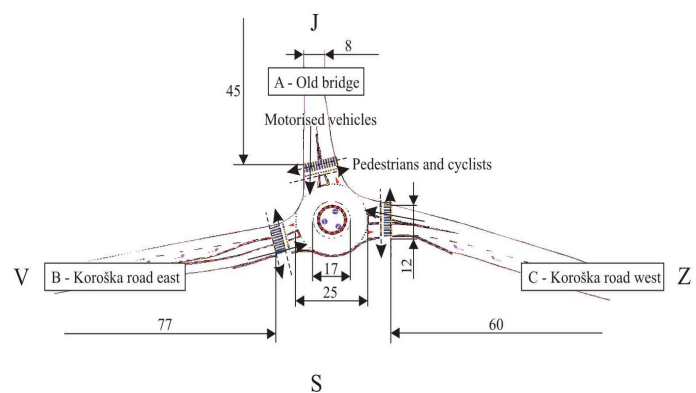

Fig. 2: Geometry of the treated roundabout (distances are in meters)

The acquired data was statistically evaluated, based on the traffic count of motorized vehicles and the 
pedestrians and cyclists for all the roads - arms A, B and $\mathrm{C}$ of the montage roundabout on the Koroska Street in Maribor. In Table 2 the data for an individual rushhour are presented, and they are connecting to the traffic flows of motorized vehicles, pedestrians and cyclists on the individual arms $\mathrm{A}, \mathrm{B}$ and $\mathrm{C}$ of the roundabout (Figure 2). Additional, average times between two arrivals of successive motor vehicles are calculated $(t=1 / \lambda)$. Case: the number of motor-vehicle arrivals within a time interval of 5 minutes $(300 \mathrm{~s})$ is 43, distributed as a Poisson statistical distribution, with the average degree of arrivals per time unit 1 equals 43 devided 300 and with the medium value of $t \cdot \lambda=43$ $\mathrm{MV}$; the average time between two arrivals of successive motor vehicles can be then determined using an exponential distribution with the medium value $1 / \lambda=$ 6.98 seconds.

Experimentally acquired input data represent the input data for the traffic flow of motorized vehicles, pedestrians and cyclists in a simulation model. Since the measurements were taken in the form of counting on an individual arm of the roundabout, the presumption has been made that the traffic flow of motorized vehicles, pedestrians and cyclists matches with Poisson's statistical distribution. In this case the times between the arrivals of two consecutive motorized vehicles, pedestrians and cyclists are distributed according to the exponent distribution. For example, on arm A in the time interval from 1010 to 1015 the traffic flow of motorized vehicles consists of 43 units, which means that motorized vehicles arrive into the arm A on average every 6.98 seconds, and are distributed according to the exponent statistical distribution.

\section{RESULTS AND DISCUSSION}

Based on the treated roundabout in Koroska Street in Maribor a simulation model was created (Figure 3). The simulation model in the programming tool AutoMod ${ }^{[12]}$ is illustrated with connection transporters, on which the motorized vehicles', pedestrians' and cyclists' traffic flow is moving. The simulation model was created from the actual geometrical data and the kinematics values (Table 1), as well as from a sample of traffic flow of pedestrians and motorized vehicles on all the roundabout's arms and all the pedestrian crossings (Table 2). The operation of the simulation model is governed by a program code (Figure 5 (a) and (b)), following the algorithm of the course in Figure 4.

The simulation begins with a process that is based on determined functions in the program code that start the operation of a roundabout. An example of generating the arrival of motorized vehicles into the arm $\mathrm{A}$ in the AutoMod ${ }^{[12]}$ programming tool is shown in Figure 5 (a) and in Figure 5 (b) for the implementation of the condition of pedestrians' and cyclists' priority. When the function »begin model initialization function « equals »true«, the process »p_old_bridge_vehicles« begins. The process consists of project variables and individual program loops that simulate the arrival of motorized vehicles depending on the average arrival value in an individual time interval of 5 minutes and the directed statistical distribution. After the defined time interval, i.e., one hour, the simulation is stopped. Generating of the rest of the traffic flow of motorized vehicles, pedestrians and cyclists is programmed similarly, according to the experimentally acquired values, presented in Table 2 . It is presumed that the arrivals of the motorized vehicles, pedestrians and cyclists are uneven, so the exponent statistical distribution has been used for generating the traffic flow. When creating the main program logic of a roundabout the general valid condition was presumed, that pedestrians and cyclists have priority with regard to the motorized vehicles. The algorithm (Figure 4) for the arrival of a motorized vehicle to the considered pedestrian crossing verifies whether there is already a pedestrian or a cyclist on the pedestrian crossing or not. In the case that there is a pedestrian or a cyclist on the pedestrian crossing $\gg$ B_block_1 current claims $<>0 \ll$, the motorized vehicle immediately stops and waits until the pedestrian leaves the crossing »wait to be ordered on Ol_waithForPath_1«. When the pedestrians' or cyclists' flow is extremely strong, waiting lines of motorized vehicles occur (Figure 6 (a) and (b)). The moment the pedestrian crossing is free »B_block_1 current claims $=0 \ll$, motorized vehicles continue with driving in the FIFO consequence according to their drive. The driving of motorized vehicles takes place until the next pedestrian or cyclist appears on the crossing, which again stops the driving of the motorized vehicles. For every passing motorized vehicle, pedestrian or a cyclist the algorithm registers (Figure 6) the basic information $» V_{\text {_waiting_time }}$ and V_number_vehicles « as follows: the number of passing motorized vehicles and the number of pedestrians. or cyclists. crossings in the roundabout, how long an individual motorized vehicle has been in the chosen arm of the roundabout (the waiting period) and if an individual motorized vehicle has been in a queue (waiting line). The main goal of the simulation analysis is to establish the capacity of the roundabout on individual arms depending on (i) the waiting period and (ii) if the waiting line of motorized vehicles in front of a pedestrian crossing is still acceptable, according to the experimentally measured information. 
Am. J. Applied Sci., 5 (1): 34-41, 2007

Table 2: Measurements of MV, $\mathrm{P}$ and $\mathrm{C}$ for an individual rush-hour

\begin{tabular}{|c|c|c|c|c|c|c|}
\hline \multirow{3}{*}{$\begin{array}{l}\text { Time interval } \\
\text { (minutes) }\end{array}$} & \multicolumn{2}{|c|}{ Arm A } & \multicolumn{2}{|c|}{ Arm B } & \multicolumn{2}{|c|}{ Arm C } \\
\hline & \multicolumn{2}{|c|}{$\begin{array}{l}\text { Rush-hour } \\
10^{10} \div 11^{10}\end{array}$} & \multicolumn{2}{|c|}{$\begin{array}{l}\text { Rush-hour } \\
14^{50} \div 15^{50}\end{array}$} & \multicolumn{2}{|c|}{$\begin{array}{l}\text { Rush-hour } \\
14^{30} \div 15^{30}\end{array}$} \\
\hline & $\begin{array}{l}{ }^{*} \mathrm{MV} \\
(1 / \lambda)\end{array}$ & $\begin{array}{l}{ }^{* *} \mathrm{P} \text { in } \mathrm{C} \\
(1 / \lambda)\end{array}$ & $\begin{array}{l}{ }^{*} \mathrm{MV} \\
(1 / \lambda)\end{array}$ & $\begin{array}{l}{ }^{* *} \mathrm{P} \text { in } \mathrm{C} \\
(1 / \lambda)\end{array}$ & $\begin{array}{l}{ }^{*} \mathrm{MV} \\
(1 / \lambda)\end{array}$ & $\begin{array}{l}\text { P in C } \\
(1 / \lambda)\end{array}$ \\
\hline $00^{00} \div 05^{00}$ & $\begin{array}{c}43 \\
(6,98)\end{array}$ & $\begin{array}{c}6 \\
(50,00)\end{array}$ & $\begin{array}{c}58 \\
(5,17)\end{array}$ & $\begin{array}{c}44 \\
(6,82)\end{array}$ & $\begin{array}{c}53 \\
(5,66)\end{array}$ & $\begin{array}{c}48 \\
(6,25)\end{array}$ \\
\hline $05^{00} \div 10^{00}$ & $\begin{array}{c}37 \\
(8,11)\end{array}$ & $\begin{array}{c}6 \\
(50,00)\end{array}$ & $\begin{array}{c}51 \\
(5,88)\end{array}$ & $\begin{array}{c}53 \\
(5,66)\end{array}$ & $\begin{array}{c}63 \\
(4,76)\end{array}$ & $\begin{array}{c}39 \\
(7,69)\end{array}$ \\
\hline $10^{00} \div 15^{00}$ & $\begin{array}{c}62 \\
(4,84)\end{array}$ & $\begin{array}{c}14 \\
(21,43)\end{array}$ & $\begin{array}{c}69 \\
(4,35)\end{array}$ & $\begin{array}{c}47 \\
(6,38)\end{array}$ & $\begin{array}{c}73 \\
(4,11)\end{array}$ & $\begin{array}{c}28 \\
(10,71)\end{array}$ \\
\hline $15^{00} \div 20^{00}$ & $\begin{array}{c}64 \\
(4,69)\end{array}$ & $\begin{array}{c}10 \\
(30,00)\end{array}$ & $\begin{array}{c}56 \\
(5,36)\end{array}$ & $\begin{array}{c}49 \\
(6,12)\end{array}$ & $\begin{array}{c}64 \\
(4,69)\end{array}$ & $\begin{array}{c}28 \\
(10,71)\end{array}$ \\
\hline $20^{00} \div 25^{00}$ & $\begin{array}{c}58 \\
(5,17)\end{array}$ & $\begin{array}{c}9 \\
(33,33)\end{array}$ & $\begin{array}{c}57 \\
(5,26)\end{array}$ & $\begin{array}{c}33 \\
(9,09)\end{array}$ & $\begin{array}{c}51 \\
(5,88)\end{array}$ & $\begin{array}{c}18 \\
(16,67)\end{array}$ \\
\hline $25^{00} \div 30^{00}$ & $\begin{array}{c}79 \\
(3,80)\end{array}$ & $\begin{array}{c}9 \\
(33,33)\end{array}$ & $\begin{array}{c}63 \\
(4,76)\end{array}$ & $\begin{array}{c}51 \\
(5,88)\end{array}$ & $\begin{array}{c}73 \\
(4,11)\end{array}$ & $\begin{array}{c}37 \\
(8,11)\end{array}$ \\
\hline $30^{00} \div 35^{00}$ & $\begin{array}{c}43 \\
(6,98)\end{array}$ & $\begin{array}{c}8 \\
(37,50)\end{array}$ & $\begin{array}{c}57 \\
(5,26)\end{array}$ & $\begin{array}{c}42 \\
(7,14)\end{array}$ & $\begin{array}{c}63 \\
(4,76)\end{array}$ & $\begin{array}{c}46 \\
(6,52)\end{array}$ \\
\hline $35^{00} \div 40^{00}$ & $\begin{array}{c}53 \\
(5,66)\end{array}$ & $\begin{array}{c}9 \\
(33,33)\end{array}$ & $\begin{array}{c}55 \\
(5,45)\end{array}$ & $\begin{array}{c}39 \\
(7,69)\end{array}$ & $\begin{array}{c}47 \\
(6,38)\end{array}$ & $\begin{array}{c}42 \\
(7,14)\end{array}$ \\
\hline $40^{00} \div 45^{00}$ & $\begin{array}{c}63 \\
(4,76)\end{array}$ & $\begin{array}{c}10 \\
(30,00)\end{array}$ & $\begin{array}{c}49 \\
(6,12)\end{array}$ & $\begin{array}{c}43 \\
(6,98)\end{array}$ & $\begin{array}{c}46 \\
(6,52)\end{array}$ & $\begin{array}{c}81 \\
(3,70)\end{array}$ \\
\hline $45^{00} \div 50^{00}$ & $\begin{array}{c}68 \\
(4,41)\end{array}$ & $\begin{array}{c}10 \\
(30,00)\end{array}$ & $\begin{array}{c}61 \\
(4,92)\end{array}$ & $\begin{array}{c}47 \\
(6,38)\end{array}$ & $\begin{array}{c}64 \\
(4,69)\end{array}$ & $\begin{array}{c}36 \\
(8,33)\end{array}$ \\
\hline $50^{00} \div 55^{00}$ & $\begin{array}{c}53 \\
(5,66)\end{array}$ & $\begin{array}{c}10 \\
(30,00)\end{array}$ & $\begin{array}{c}55 \\
(5,45)\end{array}$ & $\begin{array}{c}29 \\
(10,34)\end{array}$ & $\begin{array}{c}58 \\
(5,17)\end{array}$ & $\begin{array}{c}54 \\
(5,56)\end{array}$ \\
\hline $55^{00} \div 60^{00}$ & $\begin{array}{c}48 \\
(6,25) \\
\end{array}$ & $\begin{array}{c}4 \\
(75,00) \\
\end{array}$ & $\begin{array}{c}73 \\
(4,11) \\
\end{array}$ & $\begin{array}{c}38 \\
(7,89) \\
\end{array}$ & $\begin{array}{c}67 \\
(4,48) \\
\end{array}$ & $\begin{array}{c}36 \\
(8,33) \\
\end{array}$ \\
\hline
\end{tabular}

*MV - motorised vehicles; **P and $\mathrm{C}-$ pedestrians and cyclists

Table 3: Comparison of the results of measuring and the simulation analysis

\begin{tabular}{lccccccc}
\hline & \multicolumn{3}{c}{ Arm A } & \multicolumn{3}{c}{ Arm B } & \multicolumn{2}{c}{ Arm C } \\
\hline & MV & P in C & MV & P in C & MV & P in C \\
Measuring & 671 & 105 & 704 & 515 & 722 & 493 \\
Simulation & 683 & 100 & 719 & 513 & 725 & 492 \\
Discrepancy & $-1,79 \%$ & $4,76 \%$ & $-2,13 \%$ & $0,39 \%$ & $-0,42 \%$ & $0,20 \%$ \\
\hline
\end{tabular}

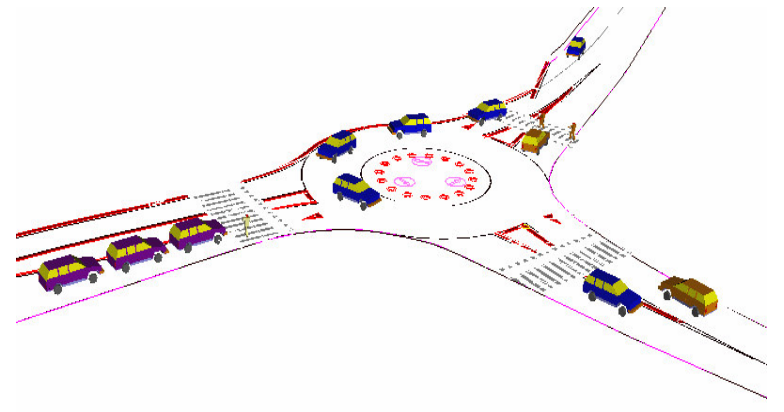

Fig. 3: Micro-simulation model of a roundabout

The results of the performed analysis for determining the waiting period and the waiting line of motorized vehicles depending on the pedestrians' and cyclists' traffic flows give basic conclusions, presented in the diagrams (a to f) in Figure 7. The simulation analysis was performed based on the geometrical values of a

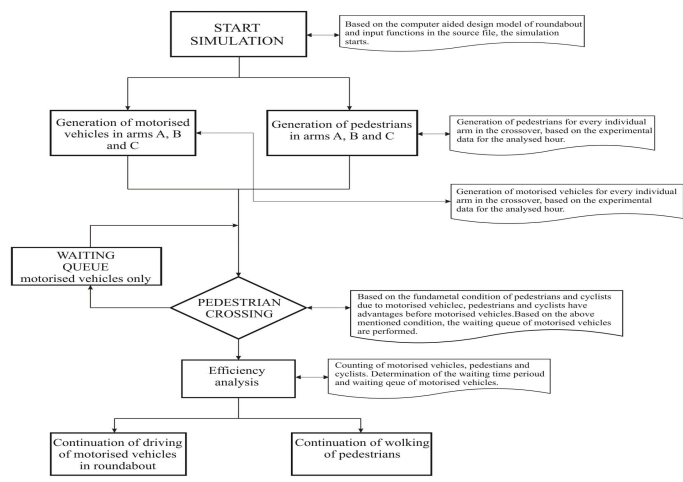

Fig. 4: Algorithm of the course of operating the simulation model of a roundabout 
Am. J. Applied Sci., 5 (1): 34-41, 2007

roundabout and the kinematics values for motorized vehicles, pedestrians and cyclists. The distribution of the waiting period (Figures $7 \mathrm{a}, \mathrm{c}, \mathrm{e}$ ) and the waiting line (Figures $7 \mathrm{~b}, \mathrm{~d}, \mathrm{f}$ ) of motorized vehicles in a roundabout is presented in Figure 7. The results of the analysis show that the number of passing motorized vehicles and the number of passing pedestrians and cyclists, according to the selected rush-hour, matches well with the experimentally gathered results (Table 3). According to the waiting-period distribution (Figures 7 $\mathrm{a}, \mathrm{c}$ and e) for motorized vehicles, proportionally low values for the individual arms of the roundabout are obvious. The waiting times in arm A are the shortest, since in the mentioned arm the pedestrians' and cyclists' flows are the smallest (arm A is located in the south part of the roundabout and represents a part of the Old bridge). According to the proportionally larger flow of pedestrians and cyclists in the arms $\mathrm{B}$ and $\mathrm{C}$, consequentially the waiting periods are longer, but do not exceed the maximum waiting time of 35 seconds. Due to the waiting lines (Figures $7 \mathrm{~b}$, d and $\mathrm{f}$ ) for motorized vehicles, proportionally smaller queues can be seen. Again, the smallest waiting lines occur in the arm A (a maximum of 6 motorized vehicles), the next is arm C (a maximum of 10 motorized vehicles) and the arm B is last (a maximum of 11 motorized vehicles). It should be emphasized that waiting lines (next to the roundabout blockage due to pedestrians' and cyclists' flows) occur due to the traffic flow of motorized vehicles with an exponent statistical distribution as well. This means that in any optional arm of the roundabout there can be a larger number of motorized vehicles, which depending on the traffic load in the roundabout cause congestion and consequently a waiting line.

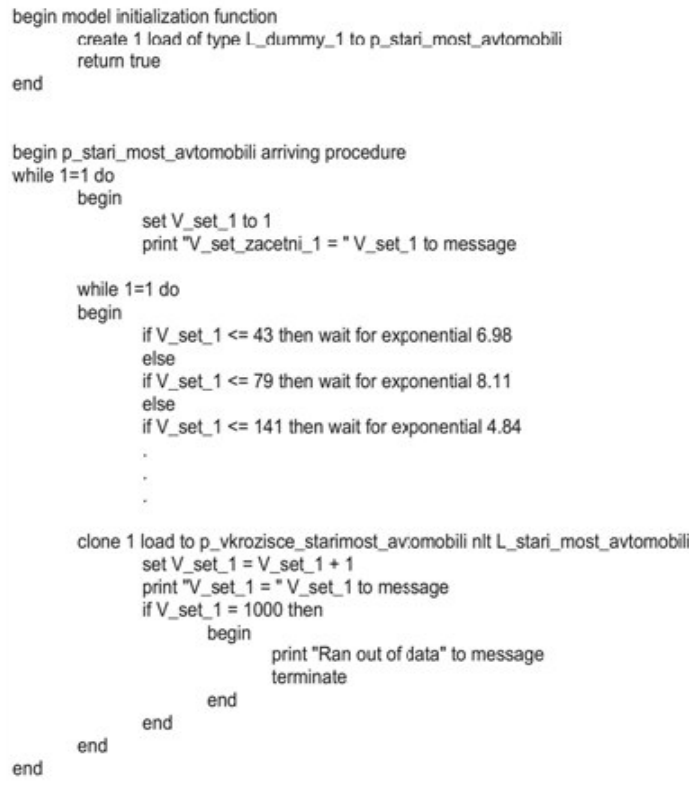

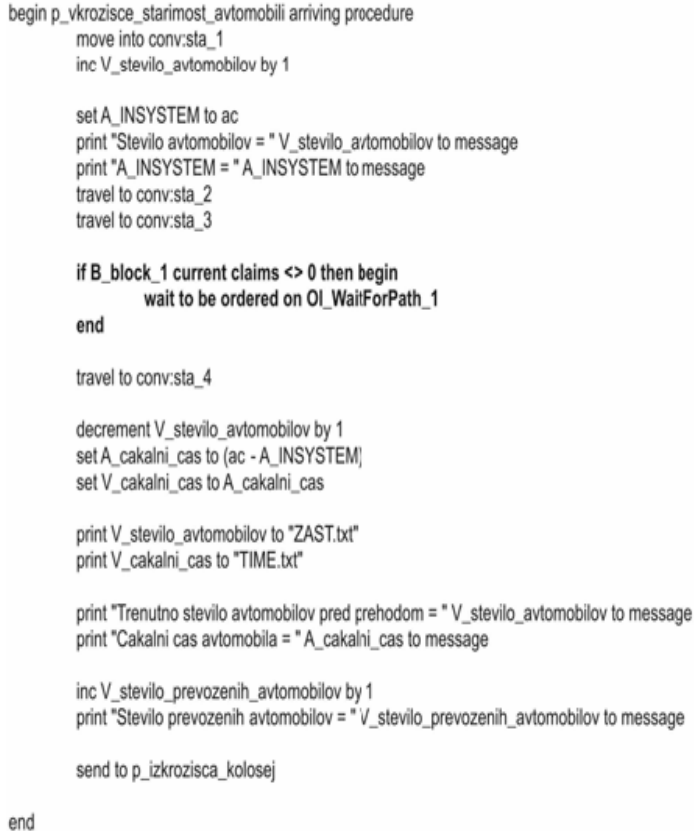

(a)

Fig. 5: The program code: (a) for generating motorized vehicles into arm $\mathrm{A}$

(b) for the implementation of the condition of pedestrians' and cyclists' priority

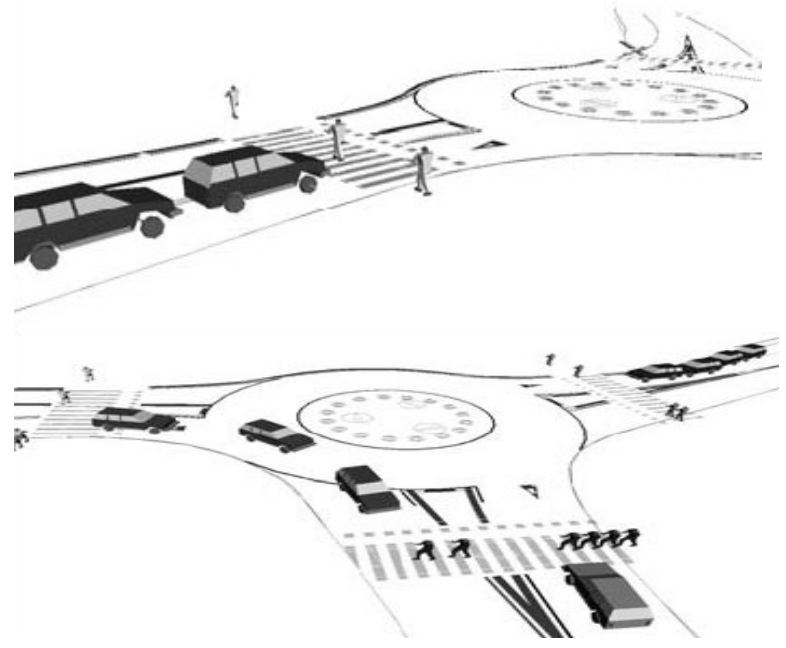

(b)

Fig. 6: An example of a waiting line of motorized vehicles because of pedestrians' flow 


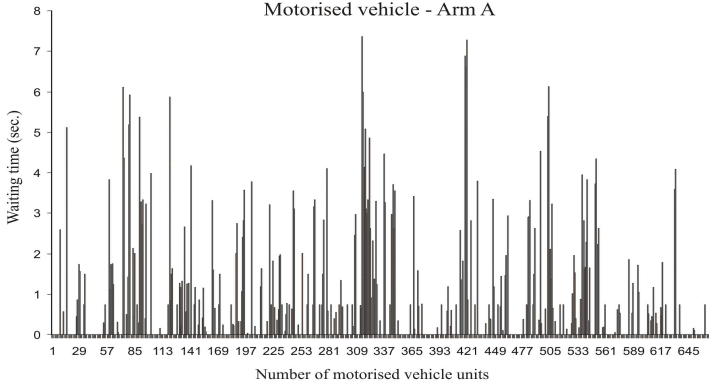

(a)

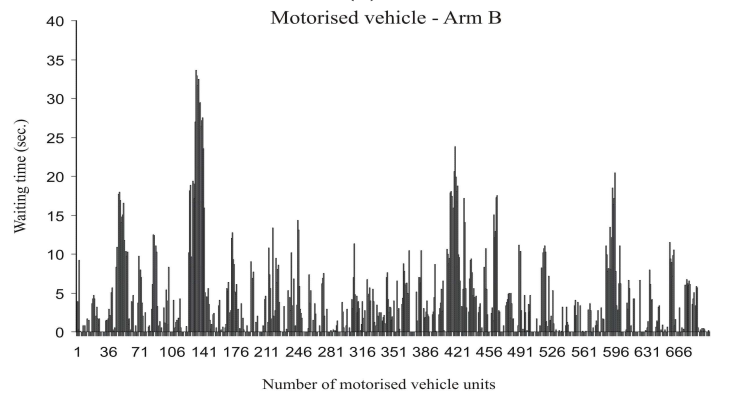

(c)

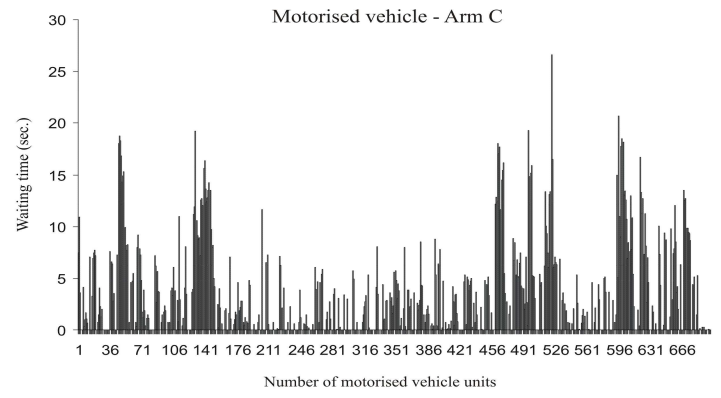

(e)

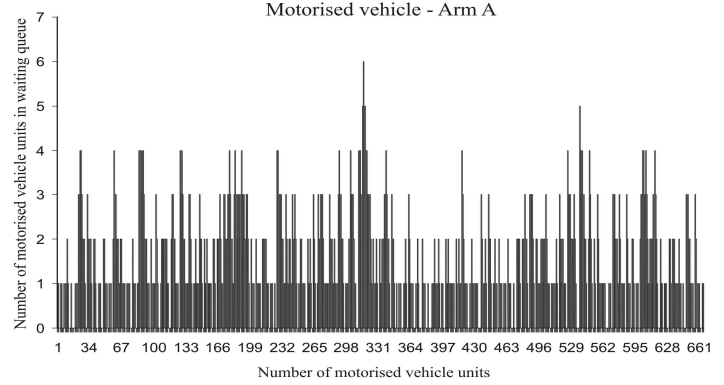

(b)

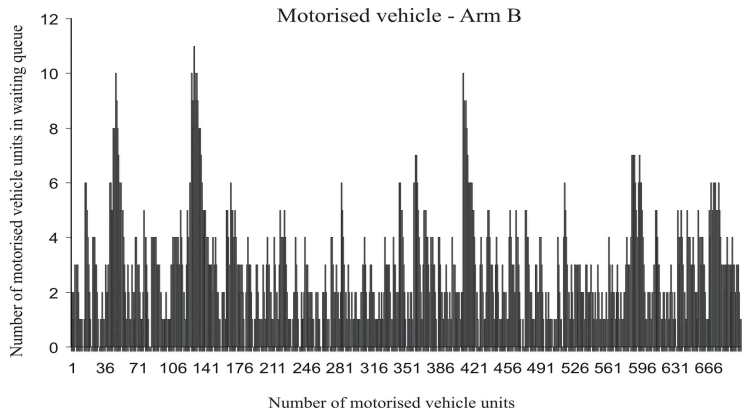

(d)

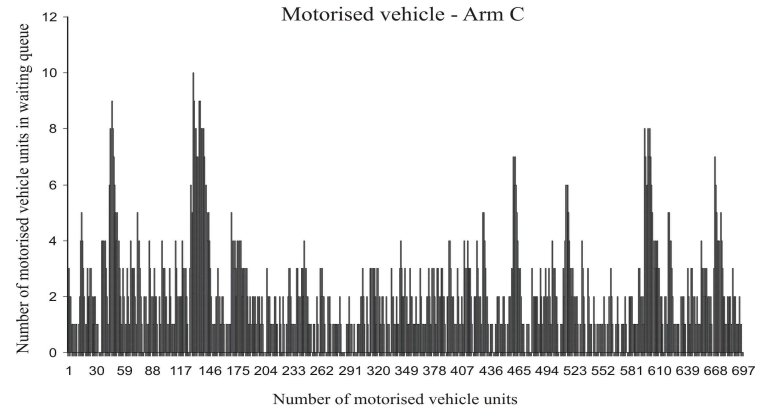

(f)

Fig. 7: The results of the analysis of the traffic flow of the motorised vehicles considering the waiting period (a, c, e) and the waiting line (b, d, f) depending on the pedestrians' and cyclists' traffic flows

\section{CONCLUSION}

The influence of the pedestrians' traffic flow, i.e., the capacity of a one-lane roundabout using discreet numeric simulations is presented. The most important goal of the performed analysis was to establish the real parameters that were later used for determining the influence of pedestrians' traffic flow on the capacity of the foreseen roundabout. In the first part of the present work the main theoretical background for the analysis of traffic flow of motorized vehicles, pedestrians and cyclists in a roundabout is presented. Since in roundabouts the pedestrian traffic flow has priority, the vehicles on entries/exits have to give way to pedestrians. During this disturbances to the entering/exiting of motorized vehicles occur, and the motorized vehicles' flow is disturbed. The more disturbed the motorized vehicles' flow is, the lower is the capacity of the roundabout. In the case the flows towards an entry to the roundabout are disturbed, the minimum capacity is not reached. In the case the flows towards an exit from the roundabout are disturbed, the maximum capacity can get exceeded. In real conditions, the entering and the exiting motorized traffic flows are disturbed simultaneously, and the congestions are transferred from arm to arm, in a clockwise direction. For this purpose, the mathematical modeling of traffic flows with the use of discreet simulations has been used 
for the analysis of the influence of pedestrians' flow on the capacity of the roundabout, considering the statistically evaluated input data for the motorized vehicles' and pedestrians' traffic flows. In the second part of the paper, a discreet numerical simulation of a roundabout is presented. The simulation model of a roundabout is general, which means it can be extended for every individual implementation, according to the chosen geometrical and kinematics sizes. The mathematical model derives from legalities of acceptable time voids in the pedestrians' traffic flow, used by the vehicles for entering/exiting a roundabout. For a determination of the traffic flow of motorized vehicles, pedestrians and cyclists the real input data for the roundabout's arms and pedestrian crossings, acquired by the traffic counting on Koroska Street in Maribor were used. The results of the measurements and simulation analyses match well, which means that the simulation analysis results give a good prediction for the evaluation of the waiting period and the waiting lines of motorized vehicles in an individual arm of the roundabout. According to the waiting-period distribution and consequentially the waiting lines depending on the number of motorized vehicles one can determine that the waiting periods and the queue of motorized vehicles are proportionally low. The established dependency can be commented with the fact that the foreseen roundabout is going to suit the expected capacity and excessive waiting periods and waiting lines of motorized vehicles will not occur. However, the simulation model presented in this work does not only present a scientific approach to mathematical modeling of roundabouts, but also presents a practical method for deciding on the suitability of introducing a roundabout in the case of a large number of pedestrians. For future research it would be sensible to upgrade the present simple model for all the arms of a roundabout, including the influence of the circular flow on the circular roadway, considering different pedestrian speeds and their arrival in more than single file.

\section{REFERENCES}

1. Tollazzi, T., Kralj, B., Destovnik, S., 2005. Analysis of the influence of pedestrian stream on roundabout capacity by using the simulation method. Suvremeni promet, 25(1/2): pp. 238-242.

2. Tollazzi, T., 1999. Reduction of the roundabout capacity due to a strong stream of pedestrians and/or cyclists. Traffic, 11(1): pp. 11-14.
3. Tollazzi, T., Lerher, T., Šraml, M., 2006. An analysis of the influence of pedestrians` traffic flow on the capacity of a roundabout using the discrete simulation method. Stroj. vestn., 52(6): pp. 359379.

4. Stone, J.R., Chae, K., 2003. Roundabouts and pedestrian capacity: A simulation analysis, transportation research board, Annual Meeting CDROM.

5. Hagring, O., 1998. A further generalization of Tanner.s formula. Transportation research Part B: Methodological. 32(6).

6. Wu, N., 2001. A universal procedure for capacity determination at unsignalized priority controlled intersections, Transportation research Part B: Methodological, 35(6).

7. Gupta, O.K. and A. Ravindran, 1985. Branch and bound experiments in convex nonlinear integer programming. Management Science, 31(12): 1533-1546.

8. Centrum voor Regelgeving en Onderzoek in de Grond-, Water- en Wegenbouw en de Verkeerstechniek: Rotondes, publikatie 79. 1993.

9. Wiedermann, R., Reiter U., 1970. Microscopic traffic simulation. The simulation system mission.

10. Fellendorf, V., 2000. Integrated modeling of transport demand, Route Choice, Traffic Flow and Traffic Emissions.

11. Dowling Associates, Inc., Guidelines for applying traffic microsimulation modeling software, Federal Highway Administration. 2003.

12. BROOKS Automation, AutoMod-User manual V 12.0, Utah. 2005.

13. Potrc, I., Lerher, T., Kramberger, J., Sraml, M., 2004. Simulation model of multi-shuttle automated storage and retrieval systems, Journal of material processing technology, 157/158: pp. 236.244. 